\title{
Coping With Dyslexia at the Junior High and High School
}

\author{
Julia Koifman \\ Beit Ekshtein High School, Rupin, Israel
}

\begin{abstract}
Dyslexia is one of the most common learning disabilities (LDs), that is why reading-disabled children must be identified in the primary school, so that special lessons and methods can correct their ability of learning and develop the necessary skills. Despite LDs, kids might be very good at art, music, or computer technology. Therefore, for the last two decades, the latter one has become very popular and made a great progress in education both in regular classes and LD ones. Audio-video activities make lessons much different from the traditional ones and provoke the students' interest. Besides, it is also a sort of learning autonomy that makes each student busy and motivated. Since kids with LDs have difficulties in reading and spelling, they can have a real help from computer technology which corrects their spelling and makes them listen to the texts while reading which makes them decipher the information much better. In addition, it can be successfully used on the exams, which is done in the range of the countries including Israel.
\end{abstract}

Keywords: dyslexia, methods, special education, reading, writing, spelling

\section{Introduction}

Childhood is the time for learning. Children, who delay breaking the phonetic code, will miss much of the reading practice that is essential for building fluency and vocabulary. As a consequence, they will fall further and further behind in acquiring comprehension skills and knowledge of the world around them. Thus, it is very important to recognize learning difficulties in the primary school, so that special lessons and methods can correct the ability of learning and develop the necessary skills. Otherwise, when kids start studying in the 7th grade, they will have more and more difficulties.

The specific signs of dyslexia, both weakness and strength, vary according to the age and educational level of a person. Thus:

A five-year-old child, who cannot learn letters well, at the age of six matches sounds and letters with difficulty. When the same kid becomes fourteen years old, he dreads reading out loud and at the age of twenty reads extremely slowly. (Goguadze, 2005)

At the same time, the child might be very good at sports, music, or art.

Dyslexic children have difficulties in reading, writing, and spelling. Therefore, they become frustrated and disappointed. Moreover, they often feel lonely, isolated, and misunderstood by their classmates. As a result, many of them misbehave, tease other kids, and answer back to adults. Their teachers wonder what they or the pupils might be doing wrong. Parents ask themselves the same questions and often feel guilty and angry.

Julia Koifman, M.A., English teacher, Beit Ekshtein High School. 
Dyslexia is an inherit subtle language disorder resulting in the poor acquisition of one or more of the basic skills underlying literacy. Having a dyslexic parent increases the probability that children will have the same problem, too. If one child in a family is dyslexic, the siblings are also likely to be dyslexic. That is why teachers, who have pupils with learning disabilities (LDs) should know the family history of school difficulties.

Teenagers with LDs need a highly structured, cumulative, and phonic-based program, using multi-sensory teaching techniques.

\section{Clues to Dyslexia in Teenagers}

When children finish elementary school and start learning in the junior high school, it causes a lot of stress. First of all, they change their environment and start studying in a different school, have different teachers and different friends. Thus, 7 th grade is a difficult time both for kids and teachers. While regular kids adapt quite easily, the kids with Attention Deficit Disorder (ADD) and Attention Deficit Hyperactivity Disorder (ADHD) can have a lot of problems.

Children become unmanageable, but at the same time, they are amazingly flexible, plastic, and ready for change and cooperation. In the cognitive development of the 12-year-olds, there has been a transition from the stage of concrete operations to the stage of formal operations, characterized by the predominance of abilities to develop strategies for finding and organizing different items of information. This stage is characterized by emerging sense of adulthood, the reorientation of identification both with parents and peers. So, students expect the rapid change of social situation.

When teachers get the classes of new 7th graders and 10th graders, they recognize the kids with ADHD symptoms:

1. Children are restless, cannot sit still in class, move their hands and legs, push each other, and chat.

2. They are impulsive: shout the answers before they hear the whole question and can hardly wait for their turn in the game. In addition, they can take other pupils' things without permission, shout on them, or even hit them.

3. Along with hyperactive kids, some of them never make any troubles in class. They listen to the teachers but misunderstand the tasks and do the exercises wrong.

4. ADHD disturbs kids to write letters and numbers correctly, they make a lot of spelling and syntax mistakes.

5. They cannot read the text loudly since they are afraid of making mistakes. Besides, they usually read slowly and can be very exhausted from reading. So, they prefer books with pictures, graphics, and charts.

6. While writing compositions in high school, they write their sentences short and non-informative in order to avoid syntax, grammar, and spelling mistakes.

7. During listening comprehension, students with LDs do not understand what they hear. Therefore, some information may be lost.

If the teachers notice a number of the forenamed symptoms, they should let the students' parents know about them. Since dyslexia often runs in families, finding out a family history of LD helps identify a vulnerable child even before the school year starts. Both teachers and families need to find the strategies in order to overcome dyslexia.

Children can memorize hundreds of words, but by the time they finish the elementary school, they will come across as many as ten thousand new words during the school year. Miles (1987) claimed that "to make 
progress in reading, they must learn how the alphabetic code works. Linking letters to sounds and then sounding out words is the only guarantee of being able to decode the thousands of new words." While the average elementary school children do it quite well, those who have LDs face serious problems and when they start junior high school, their progress in English is very little. Many of them might give up and stop learning English.

According to Shaywitz (2005), many people confuse ADHD and dyslexia. "While dyslexia is a language-based disorder affecting reading, ADHD is a problem reflecting allocating, focusing and sustaining attention." The statistics show that between $12 \%$ and $24 \%$ of those with dyslexia also have ADHD.

The diagnosis of LDs reflects a reading difficulty that is unexpected for a person's age, intelligence, and level of education. It is a clinical diagnoses based on a thoughtful synthesis of information-from the student's personal and family history; from observations of speaking, reading, and writing; and from the tests of reading and language. Identification of the problem of LDs is the key to protect children against reading failure in their new surroundings after they finish elementary school and start junior high one. The sooner a diagnosis is made, the quicker a student can get help, and the more likely the self-esteem is kept normal.

Knowing as much as possible about the child's intelligence level is essential for accurate diagnosis. A dyslexic person struggles with spelling and writing, and often those difficulties need tutoring and teaching beyond their special education classes.

\section{Curriculum Needs for Students With Dyslexia}

Reading is a system of communication based on associating letters and sounds and interpretation of written symbols and spoken language. An aspiring reader must build reading vocabulary, so that eventually the person can read complex, long, or unfamiliar words. "Since he has stored each letter that has been transformed into a sound, he has accumulated within his brain an entire storehouse of letter representations" (Burani, 2008). If students lack this skill, their reading is very slow or they reads letter by letter.

"While learning to read enhances awareness of the sound structure of words, phonological awareness is distinct from either phonics or the ability to read and spell" (Moats, 1994). A slow reader or a person who confuses letters, cannot perform a variety of listening activities, such as rhyming, tapping out the number of syllables in a word, or listing words that begin with a certain sound. Inability to perform these tasks in the elementary school reveals a weak foundation for learning an alphabetical writing system. Thus, in the junior high school, such kids misunderstand texts and misspell words and in the high school, they lack skills necessary for the matriculation exams. In other words, they are not able to complete tasks that require reading and listening comprehension. Moreover, misspelling and poor writing skills make a high school student unable to write compositions.

It is known beyond doubt that the degree of awareness of the phonological structure of words is the best predictor of a child's subsequent reading success. To be a skilled reader, a child needs to appreciate that words are comprised of individual speech sounds that are represented by letters and letter combinations (e.g., "mat," "mate," and "mark"). Lacking the knowledge that letters or letter combinations correspond to speech sounds, a regular learner will find English writing system very complicated, not to mention a LD one. If a child is lacking in speech sound awareness, it should be taught along with instruction in letter-sound relationships. Teaching methods in remedial classes need to incorporate direct instruction in the structure of language in order to provide the foundation children become need to become skilled readers and spellers. 
Another area of limited structural awareness for a weak reader and speller is appreciation of the morphemic structure of words. Morphemes are the smallest meaningful units in words. They may be whole words (e.g., "foot" and "finger") or parts of words (e.g., un + teach + able; medic + al). Awareness of the morphemes in words facilitates both reading and spelling, and not only for the advanced reader. To progress to more advanced stages of reading and spelling, the learner must be aware that the spelling of meaningful word parts often stays constant even when pronunciation changes from one word to another, as in "compete" and "competition," "resign" and "resignation," and "define" and "definition" (Moats, 1994).

Some errors in spelling are morphologically based. The researcher has noticed that over-use of morphological analogies by Hebrew-speakers is a common source of spelling errors, such as "procedure" ("proceed"), "pronounciation" ("pronounce"), and "rememberance" ("remember"). Unlike Hebrew, whose morphology is logically explained, English morphology has a lot of exceptions. Besides they often ignore capital letters because there are not any in Hebrew, some errors in reading may be explained as a consequence of a faulty morpheme analysis, e.g., scar/city (scarcity) and car/pet (carpet). Finally, there is clear evidence from children's acquisition that they make morphologically based generalizations. The regularization of irregular verbs is a standard example.

Unlike skilled readers, dyslexic teenagers benefited from morphological structure in reading aloud words. It is proposed that the morpheme is a unit of intermediate grain size that proves useful in processing all linguistic stimuli, including words, in individuals with limited reading ability who did not fully develop mastering of whole-word processing. For example, first, they should learn the spelling and the pronunciation of the word "black." Then, it will be easier to learn a list of compound words, such as "blackbird" (a black bird), "blackboard" (a black board), or "blackberry" (a black berry). Thus, using lexical decision tasks and other similar techniques, many dyslexic students decompose semantically and phonologically transparent words into their constituent morphemes. Tactile method should also be used in special educational classes, so that students will be able to touch the words.

Students with dyslexia encounter difficulties in their classrooms ranging from a lack of confidence to problems with teacher training to poor curriculum materials. Focusing on a child's ability to spell so that he can effectively communicate in his writing is vital to his success throughout his education. The appropriate lessons are vital to that goal, as is a continuing focus on spelling instruction even after special education services are complete. (Jones, 2010, p. 25)

Besides, they should be given extra time in exams because they need to have any kind of chance of answering all the exam questions, especially in the matriculation exams. Since almost all dyslexics read and write at about half the speed of non-dyslexics the extra time allows them to find answers to the questions while reading comprehension, rub out and rewrite incorrect spellings and improve the sentences of the composition.

\section{Helping Students With LDs}

If a teenager has been diagnosed as a dyslexic, it is important to organize some assistance as soon as possible. Otherwise, the individual can very quickly fall behind and get discouraged. The sooner some assistance can be organized the better. It is good practice to get an assessment done with a qualified person, to gain a clear idea of the nature of the individual student's dyslexia. It is important to get specific help, for example, occupational therapy whose goal is to train general literacy, memory, and organizational skills. Tutoring students with LDs should be defined by the nature of their dyslexia. 
Generally, assisting dyslexic students should be integrated to combine different approaches: with parents, with school teachers, medication, psychotherapy, psycho-pedagogical correction, etc.. It must be remembered that the application of modern techniques to help children achieve significant results to gradually overcome the difficulties in learning, behavior, and communication. Remedial teachers need to remember that they have to allow their students to demonstrate their knowledge on the subject at or above grade level, even though they have not yet mastered reading, writing, or spelling at grade level. In other words, teachers give kids success-oriented materials.

Share (1997) claimed that "When perceptual and memory tasks do not require the processing of speech-based (phonological) information, dyslexics perform as well as normal readers." This happens when short-term memory for a sequence of digits is poor.

But when the same task is given in a visual-spatial format - that is, requires reproducing a tapped sequence of randomly arranged blocks in the correct order - there is no evidence of memory difficulties. Similarly, when asked to make semantic decisions about the same pictures, they have difficulty naming (e.g., Is a cauliflower a fruit?), dyslexics perform just as well as good readers. (Goguadze, 2005, p. 52)

Thus, different kinds of memory games work very well to increase interest studies and motivation to make more and more progress.

Class work should be organized in an interesting and motivating way. Since students with LDs often cannot read texts loudly, the teacher can do it to the class. After each paragraph, the teacher can ask somebody to explain what it is about, it is also acceptable to do it in their mother tongue. If the students know enough vocabulary, they try to do it in English. Moreover, using pictures, diagrams, and other visual aids can ease the reading comprehension significantly. In this way, students can predict what the text is going to be about and realize the plot structure of the story even if they lack vocabulary. After reading, it is helpful to use such exercises as match up, fill-in-the-blank, or writing short answers. Before the lesson is over, the teacher should make a summary. For example, the teacher can ask which new words the students have studied and how they are spelt. Moreover, the teacher can ask what grammar they have already known and how it helped them to understand the text.

According to Davis (1992), many dyslexic kids are talented in music. Therefore, singing songs is a good way to learn new words and grammar rules. Thus, when the high school students cannot understand the difference between past simple and past progressive tenses, one of the United States' most famous folk songs "This Land Is Your Land" may help a lot.

\footnotetext{
When the sun was shining, and I was strolling,

And the wheat fields waving and the dust clouds rolling,

As the fog was lifting, a voice was chanting:

This land was made for you and me.
}

This song lets them know that two and more long actions in the past are used in the past progressive.

Teachers should never force students with dyslexia to read out loud in front of the class. If for some reason this is absolutely necessary, for example, if the teacher plans the drama lesson in English, students should be warned in advance and know exactly which parts of passage they will have to read so that they can practice beforehand. Besides, it is not a good idea to give as much homework as in regular classes, because it takes a dyslexic student three to four times longer to complete the same assignment as a child that is not dyslexic. A 
maximum amount of time should be agreed upon between the teacher and the parent for the completion of homework. The students should only be required to work on homework for the maximum amount of time.

In addition, copying tasks need to be limited or eliminated in the special education classes. It would be beneficial to each dyslexic student to have a copy of the teacher's notes. Copying information from the board takes a dyslexic student much longer, and often is illegible. Jones (2010) claimed that "If a copy of the teacher's notes is not available, copying notes from a student gifted at taking notes is a good second choice."

Test and quizzes in the junior high school should be offered in the following way. The list of vocabulary words for fill-in-the-blank sections must be placed at the top of the exam. Dyslexics often know the answer but have a problem retrieving the specific word without a list to choose from. Multiple-choice questions are also difficult for dyslexic students due to the volume of reading required to answer them correctly. If the test is read and alternative measures are made for the recording of answers, essay and multiple-choice tests can be used successfully.

To make students with LDs succeed in the matriculation exams, Houk (2007) offered the following recommendations. First, students with LDs must be given extra time to read the questions, formulate an answer in their heads, and write it down on paper. Second, the examiners should practice oral testing with the help of a reader or a tape recorder. Tests are read to the students and they are allowed to give answers orally. Third, it is not appropriate to take spelling mistakes and poor handwriting into consideration when assigning a final grade.

Finally, teachers should listen to their students who can explain strategies and techniques that help them learn more effectively and get better on the upcoming exams. In this way, it is easier to incorporate into a classroom. When working in the special education classes, it is important to remember that the kids and the teacher are a team which needs to work together for its benefit. Open dialogue is extremely important for students with LDs to succeed that will ensure a happy and productive year for them and help them in their future life when they decide to study at university and use the skills of learning they have developed at school.

\section{Conclusion}

It is not always easy to recognize dyslexia in teenagers. A teenage pupil may be quick thinking but feel they have a block with reading and writing or find it difficult to express their ideas clearly. They may be disorganized, forgetful, or feel frustrated by these things; this can be an indication of dyslexia. Dyslexia shows itself in a variety of ways, including weaknesses in memory, poor sequencing ability, and hand-eye skills. It can be hereditary or the result of specific circumstances, such as childhood illnesses and manifests itself with different levels of severity.

Adolescence is characterized by maximalism, which is extreme. It seems that everything that happens is forever, including low grades and lack of success in school. While in 7th-9th grades, kids might display indifference to studies. High school students begin to consider the studies as the necessary basis or prerequisite for future professional activities. Therefore, in the high school, comparing with the junior high classes, the interest of learning increases. When the students have to take the matriculation exams, they are more motivated to succeed as well as they want to be independent.

Since reading is so essential to learning and overall success in school setting, difficulties in reading create a lot of problems, such as behavioral disturbances, problems with attention, low self-esteem, and declining vocabulary and general knowledge. So, it is very important to use appropriate learning strategies in special education classes, such as multisensory approach to teaching new materials. Thus, audio-visual aids are good 
while learning new vocabulary and reading comprehension, tactile method can be useful in memorizing morphemes, and singing songs can help both pick up new words and grammar rules.

It is important to be alert to the ways in which teenager's dyslexia affects them and to adopt positive strategies for dealing with them. Teenagers may become resistant to assistance if it is offered in the wrong way. That is why help with dyslexia should be provided to teenagers very carefully, to make sure that they can cope with the disability well enough, despite it can often be extremely difficult owing to a number of factors mentioned above. Anyway, remedial teachers must try their best to create appropriate relationships with their students, listen to them and help them discover their individual talents. Therefore, they will have a motivation to learn English well, to get their matriculation certificates, and to succeed in any course of university study or career.

\section{References}

Burani, C. (2008). Morpheme based reading aloud. Retrieved from http://www.eric.ed.gov/ERICWebPortal/search/detailmini.jsp? _nfpb=true\&_\&ERICExtSearch_SearchValue_0=EJ796533\&ERICExtSearch_SearchType_0=no\&accno=EJ796533

Davis, R. D. (1992). 37 common characteristics of dyslexia. Retrieved from http://www.dyslexia.com/library/symptoms.htm

Goguadze, T. (2005). Signs of dyslexia in teenagers (Doctoral dissertation, Moscow State University).

Houk, M. D. (2007). Tips to help dyslexic students. Retrieved from http://www.suite101.com/content/tips-to-help-dyslexicstudents-a34071

Jones, M. (2010). Helping students with dyslexia improve spelling. Retrieved from http://www.suite101.com/content/teachingdyslexic-children-a212881

Miles, T. R. (1987). Understanding dyslexia (Doctoral dissertation, Department of Psychology, Bangor University).

Moats, L. C. (1994). The missing foundation in teacher education: Knowledge of structure of spoken and written language. Vermont: The Greenwood Institute Putney.

Moores, E., \& Andrade, J. (1997). Ability of dyslexic and control teenagers to sustain attention and inhibit responses. Retrieved from http://eprints.aston.ac.uk/5735/1/mooresandandradeauraversion.pdf

Share, D. L. (1997). Understanding the significance of phonological deficits in dyslexia (Doctoral dissertation, Faculty of Education, University of Haifa).

Shaywitz, S. (2005). Overcoming dyslexia. New York, N.Y.: A Division of Random House, Inc.. 